\title{
Early expression of chromogranin A and tyrosine hydroxylase during prenatal development of the bovine adrenal gland
}

Accepted: 18 July 1994

\begin{abstract}
The present study was undertaken to define the temporal pattern and distribution of cells positive for chromogranin $\mathrm{A}(\mathrm{CgA})$ and tyrosine hydroxylase $(\mathrm{TH})$ in various developmental stages of fetal bovine adrenal gland. $\mathrm{CgA}$ is an acidic protein, co-stored and co-released with amines and a variety of peptide hormones and neurotransmitters in dense core vesicles of neural and endocrine cells and can be used as a marker for these cells and their malignant counterparts. TH is the rate-limiting enzyme in catecholamine biosynthesis and reflects noradrenergic differentiation. The expression of $\mathrm{CgA}$ and $\mathrm{TH}$ was examined by immunohistochemistry. $\mathrm{CgA}$ immunoreactivity appears first in 35day-old bovine fetuses. By the end of the second month, CgA-labelled cells are scattered throughout the entire primordium of the adrenal gland, and at a fetal age of 85-91 days most of these cells concentrate in the developing adrenal medulla. From this stage onwards, immunoreactive cells of the marginal zone of the medulla exhibit significantly stronger $\mathrm{CgA}$ immunoreaction than the central area. TH immunoreactivity appeared in the adrenal primordium for the first time at the end of the second month of gestation. The distribution pattern of TH-positive cells was similar to that described for $\mathrm{CgA}$, and no significant differences in topographical arrangement between $\mathrm{TH}$ - and $\mathrm{CgA}$-positive cells can be detected. The results show that bovine adrenal chromaffin cells express $\mathrm{CgA}$ already during their earliest stages of development and prior to $\mathrm{TH}$. The stronger immunoreaction of marginal adrenal medullary cells suggests an adrenalcortical effect of glucocorticoids on the expression of $\mathrm{CgA}$.
\end{abstract}

I. Totzauer $(\unrhd) \cdot$ W. Amselgruber $\cdot$ F. Sinowatz Institut für Tieranatomic II, Universität München, Veterinärstrasse 13, D-80539 München, Germany, Fax: + 49-(0)89-2180-2569

M. Gratzl

Abteilung Anatomie und Zellbiologie, Universität Ulm, D-89069 Ulm, Germany
Key words Chromogranin A - Tyrosine hydroxylase Development - Adrenal gland · Bovine fetus

\section{Introduction}

Chromogranins are co-stored and co-released with amines and a variety of peptide hormones and neurotransmitters in dense core vesicles of neural and endocrine cells (Winkler and Fischer-Colbrie 1992). They can be used as markers for these cells and their malignant counterparts. Chromogranins were originally detected in the adrenal medulla (Banks and Helle 1965) and have been isolated, characterized, sequenced and analysed by many other authors. Despite the widespread distribution of chromogranins in endocrine and nervous tissue, the function of $\mathrm{CgA}$ remains unclear.

The following functions of $\mathrm{CgA}$ have been postulated: CgA may be involved in $\mathrm{Ca}^{2+}$ uptake (Erhart et al. 1986; Reiffen and Gratzl 1986a, b), packaging, sorting and release of secretory products (Benedum et al. 1986); it may serve as a precursor for small regulatory peptides (Benedum et al. 1986) or act as a prohormone (Eiden 1987). Determination of $\mathrm{CgA}$ in serum and tissue sections is therefore of diagnostic value in classical endocrine tumours, in hormone-negative tumours and in endocrine tumours (Deftos 1991). The expression of $\mathrm{CgA}$ has been studied in human and rat fetuses (Kent and Coupland 1989; Molenaar et al. 1990). These investigations revealed profound differences in the time course of its expression during prenatal development. In human fetal adrenal gland, CgA expression could be detected in 6-week-old fetuses (Molenaar et al. 1990); in rat fetal adrenal gland, $\mathrm{CgA}$ expression was found at day 17 of gestation (Seidl and Unsicker 1989). In the present study we could detect, as in human fetuses, early prenatal $\mathrm{CgA}$ expression in bovine adrenal gland.

Tyrosine hydroxylase (TH) is the rate-limiting enzyme in catecholamine biosynthesis. It is highly expressed in noradrenergic neurons in postnatal sympathetic ganglia, and is a sensitive index of growth and 
differentiation of sympathetic neurons (Cochard et al. 1978). Noradrenergic specialization can be well documented by the immunohistochemical appearance of $\mathrm{TH}$. In the rat, the immunohistochemical appearance of TH was initially detectable in sympathetic primordia at 12.5 days of gestation (Cochard et al. 1978). By 13.5 days, cells containing $\mathrm{TH}$ were observed between the sympathetic ganglia and developing adrenal gland, and within the adrenal itself (Bohn et al. 1981).

In this study we give for the first time the exact immunohistochemical distribution of CgA- and TH-immunoreactive cells in the adrenal gland during the prenatal development of cattle.

\section{Materials and methods}

Tissue collection

We investigated 22 bovine fetuses at 17 developmental stages, ranging in age from day 35 to day 260 (crown-rump length from $1.5 \mathrm{~cm}$ to $86 \mathrm{~cm}$ ). Immediate post mortem fixation was performed in Bouin's fluid at the municipal slaughterhouse in Munich. After fixation in Bouin's fluid for $6 \mathrm{~h}$ and subsequent dehydration, the tissue blocks were embedded in Paraplast according to standard procedures (Romeis 1989). Serial sections $(5 \mu \mathrm{m})$ were cut on a Leitz microtome and collected on ethanol-cleaned glass slides. Sections stained with haematoxylin and eosin were routinely evaluated with the light microscope.

Immunohistochemical procedures

The polyclonal antiserum directed against bovine CgA (Erhart et al. 1986) was kindly provided by D. Aunis, Strasbourg, and the monoclonal antibody against TH (Rohrer et al. 1986) was purchased from Sigma (München). Both the ABC-technique (Hsu et al. 1981) and PAP-technique (Sternberger 1986) were applied. The endogenous peroxidase activity of the deparaffinized sections was first blocked with $1 \%$ hydrogen peroxide in methanol for $30 \mathrm{~min}$. After washing three times in phosphate-buffered saline (PBS, 0.01 M, pH 7.4), the sections were incubated with $0.1 \%$ bovine serum albumin (BSA, Fraction V, Sigma) for $20 \mathrm{~min}$. The sections were then washed again in PBS and incubated for $30 \mathrm{~min}$ with normal goat serum or $30 \mathrm{~min}$ with normal rabbit serum. Subsequent incubation for $12 \mathrm{~h}$ (humid chamber, $4^{\circ} \mathrm{C}$ ) with the primary antiserum to $\mathrm{CgA}$ or the primary antiserum to $\mathrm{TH}$ was carried out at a working dilution of 1:5000 (CgA) or 1:2000(TH). The slides, which were incubated with the primary antiserum against $\mathrm{CgA}$, were then treated with biotinylated goat-anti-rabbit antibodies (Amersham, diluted 1:200 in PBS) and streptavidin-biotin-horseradish-peroxidase complex $(7.5 \mu \mathrm{l} / \mathrm{ml}$ PBS). Sections, which were incubated with the primary antiserum against $\mathrm{TH}$ were then treated with a secondary rabbit anti-mouse antibody (Euromedex, France, working dilution 1:100 in PBS) and a PAP complex (mouse). Peroxidase activity was visualized using 3,3-diaminobenzidine-hydrogen-peroxide reagent. Selected slides were counterstained with hemalaun.

The specificity of the immunocytochemical reactions was assessed by (1) replacement of the primary antibodies with buffer; (2) substitution with non-immune goat or rabbit serum and (3) incubation with diaminobenzidine reagent only, to exclude the possibility of non-suppressed endogenous peroxidase activity. Samples from adult bovine adrenal medulla served as positive controls for immunostaining.

\section{Results}

Histotopography of Chromogranin A

(CgA)-immunoreactivity

Immunoreactivity for $\mathrm{CgA}$ was first observed in immunoreactive neuroblasts migrating in the mesenchyme between the descending aorta and lateral to the mesonephros (Fig. 1 a) to the developing ganglia of the sympathic system and to the adrenal primordium in a fetus at day 35 of gestation. Additionally, clusters of $\mathrm{CgA}$-immunoreactive cells were found in the area of the adrenal primordium (Fig. 1 b). These CgA-positive cells were intermingled with the developing cell cords of the primordial adrenal cortex, which arise from the coelomic epithelium at this time. In most of the sections, a few CgA-positive cells were also observed in close vicinity to the developing central vein. During the following days the adrenal primordium grew rapidly (day 40), and many CgA-positive neuroblasts invaded the cortex of the fetal adrenal gland. In the medullary zone the heavily immunostained cells were arranged in a cordlike fashion and formed cell clusters (Fig. 2). At a fetal age of 85-91 days, CgA-immunoreactivity was restricted mainly to neuroblasts located in the adrenal medulla, which can at this stage easily be distinguished from the fetal adrenal cortex. In the differentiating cortex, which at this stage shows a clearly differentiated zona glomerulosa, only a few individual cells were immunoreactive. Most of these cells were close to capillaries, which separated the cell cords of the developing cortex. From this stage onwards, neuroblasts located at the boundary between the fetal cortex and medulla exhibited stronger immunolabelling for $\mathrm{CgA}$ than the cells of the inner medullary zone. After another 20 days (day 105-120), the difference in the intensity of the immunoreactivity between outer and inner medullary zone became even more pronounced and could be clearly demonstrated in all the following developmental stages (Fig. 3).

At the age of 184-187 days, two zones characterized by their differences in $\mathrm{CgA}$ immunoreactivity could also be distinguished in bovine adrenal medulla by conventional histology. The outer zone consisted of cells with pale, vacuolated cytoplasm, whereas cells of the inner layer had a more eosinophilic cytoplasm. The immunoreactivity of $\mathrm{CgA}$ was restricted to these two cell populations. Other cell types of the adrenal gland, such as fibrocytes, nerve cells, and endothelial cells of the well-developed capillary system, exhibited no $\mathrm{CgA}$ immunoreactivity.

\section{Histotopography of tyrosine hydroxylase (TH)-immunoreactivity}

In early stages of development (day 35) the intensity of immunoreaction for $\mathrm{TH}$ was very weak. TH-labelled cells could be detected first at a fetal age of 40 days in 

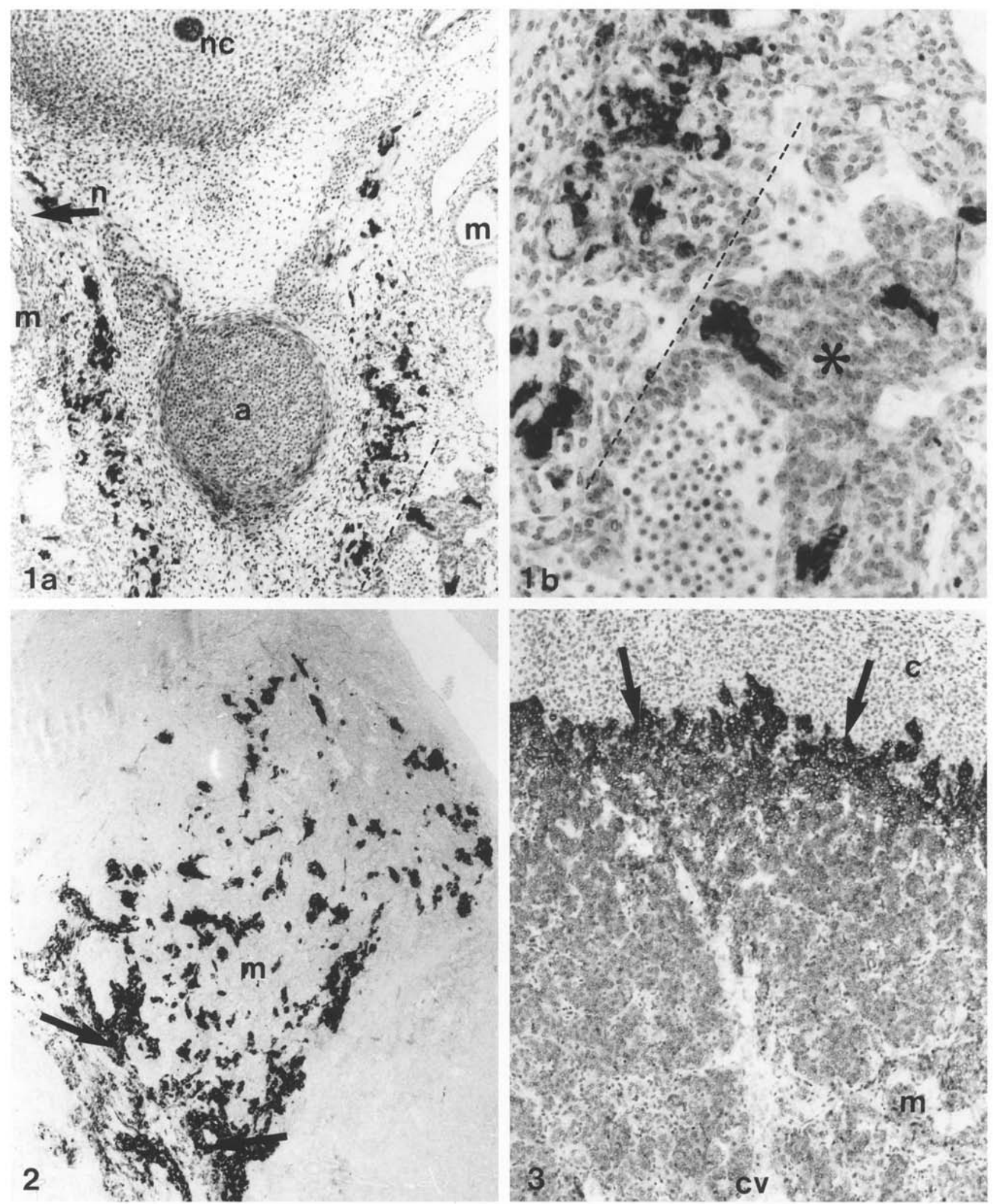

Fig. 1 a Chromogranin A-(CgA-) immunoreactivity in cell-clusters lateral to the descending aorta $(a)$ and medial of the mesonephros $(m)$. ( $n$ nerve fibers, $n c$ notochord). Bovine fetus at day 35 of gestation. The border between the adrenal primordium and developing sympathetic ganglia is marked by dotted lines. Cross-section, counterstained with hemalaun. $\times 160$. b Detail of a. Clusters of CgA-labelled cells around and within the adrenal primordium $(*) . \times 650$

Fig. 2 CgA-positive cells migrating through the cortex $(\rightarrow)$ forming the adrenal medulla $(m)$. ( $a$ aorta). Bovine fetus at day 40 of gestation. Cross-section, counterstained with hemalaun. $\times 160$

Fig. 3 Adrenal medullary chromaffin cells adjacent to the cortex $\rightarrow \rightarrow$ exhibit a stronger immunostaining for $\mathrm{CgA}$. Bovine fetus at day $105-120$ of gestation ( $c$ cortex, $m$ medulla, $c v$ central vein). Cross-section, counterstained with hemalaun. $\times 200$ 

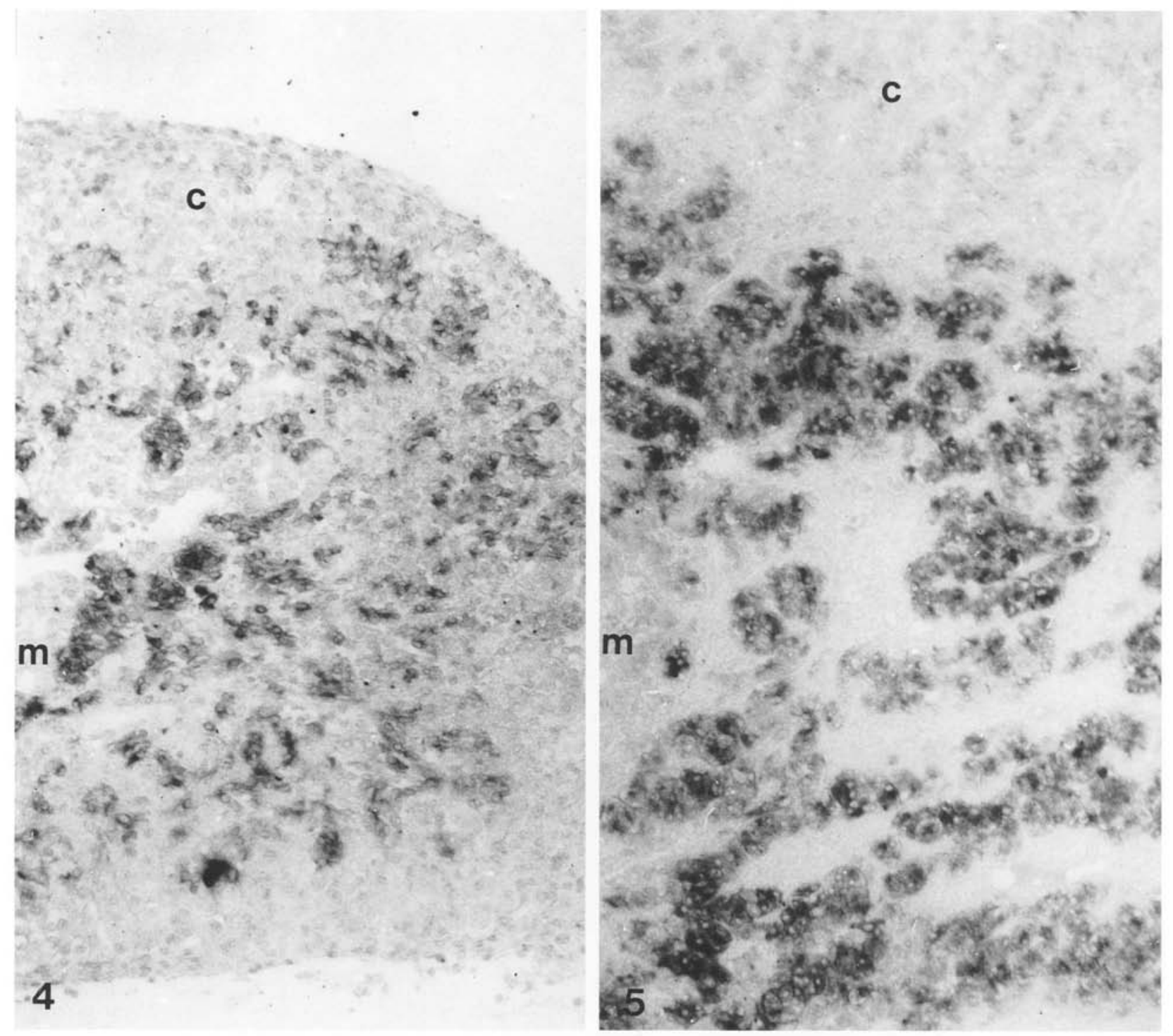

Fig. 4 TH-positive cells in the developing adrenal gland of a bovine fetus at day 60 of gestation. Cross-section, not counterstained ( $c$ cortex, $m$ medulla). $\times 320$

Fig. 5 TH-positive cells in the outer part of the adrenal medulla. Adrenal of bovine adult. Cross-section, not counterstained ( $c$ cortex, $m$ medulla). $\times 320$

cells localized in the vicinity of developing nerve fibres. Cells of the adrenal primordium were consistently negative at this developmental stage. In the $3 \mathrm{rd}$ month of gestation, TH-positive cells were detected for the first time in the adrenal primordium. The intensity of the immunoreaction was weak (Fig. 4) at this stage and increased during the following developmental stages (Fig. 5). Most of the labelled cells were found in the medullary primordium, and the pattern of TH-positive cells was similar to that described for $\mathrm{CgA}$.

\section{Discussion}

The present study was intended to collect precise data on the occurrence and distribution of $\mathrm{CgA}$ - and $\mathrm{TH}$ positive cells in various developmental stages of fetal bovine adrenal gland. We found immunoreactive $\mathrm{CgA}$ in the bovine adrenal primordium first at day 35 of development, at which stage the adrenal medulla has not yet formed. Expression of $\mathrm{CgA}$ appeared earlier than that of $\mathrm{TH}$, which was coexpressed after 60 days of gestation. Immunostaining for $\mathrm{TH}$, which is a marker enzyme for noradrenergic cells (Bohn et al. 1981) and the rate-limiting enzyme in the catecholamine pathway, indicates a catecholamine synthesis in these cells already at the end of the 2 nd month of pregnancy. The expression of TH in neuroblasts at this time is in accordance with previous observations on rat and human embryos. Molenaar et al. (1990) postulate that migrating neural crest cells, which express TH when they traverse the adrenal cortex on their way to the adrenal primordium, 
coexpress $\mathrm{CgA}$. The early appearance of $\mathrm{CgA}$-positive cells in areas corresponding to the later para-aortic sympathetic ganglia and the adrenal primordia of fetal bovine adrenal glands takes place in the 6th week of pregnancy - at the same time as described for human embryos (Molenaar et al. 1990). In human embryos, $\mathrm{CgA}$-expression is slightly preceded by immunostaining for $\mathrm{TH}$. At 9 weeks, positive staining for $\mathrm{CgA}$ and $\mathrm{TH}$ is confined to "large cells" in the adrenal medulla, which are considered to be progenitors of chromaffin cells. In 14-week-old fetuses, clusters of small cells resembling adult sympathic ganglion cells were immunoreactive for $\mathrm{TH}$, but not for CgA (Molenaar et al. 1990).

In our studies on bovine embryos we were not able to detect TH prior to day 60 of gestation. In accordance with the results of Molenaar et al. (1990), we also found that the pattern of immunoreactivity for TH was generally the same as that observed for CgA. The chromaffin (TH and $\mathrm{CgA}$ ) and the neuronal (TH) markers (Molenaar et al. 1990) of the adrenal medullary cells are expressed in the first 2 months of bovine development, indicating an early prenatal start of adrenal catecholamine synthesis.

Concomitant with the development of the adrenal medulla, differences in the immunoreactivity for $\mathrm{CgA}$ are seen in the medullary cells. Weak and uniform staining of the cytoplasm seen in the 6th week of development gives way to a distinct staining pattern in the 3rd month of gestation. Cells of the outer layer are strongly immunoreactive, whereas those of the central area of the medulla are only slightly stained. Strong immunostaining for $\mathrm{CgA}$ in cells that are located in the periphery of the bovine adrenal medulla suggests that these cells contain a high concentration of CgA. It is known that increase of $\mathrm{CgA}$ biosynthesis and adrenaline production during fetal development are both influenced by the glucocorticoids of the adrenal cortex (Winkler and FischerColbrie 1992). Our data suggest that the strong immunoreactivity of peripheral cells of the adrenal medulla is due to the influences of the initial glucocorticoid synthesis in the adjacent regions of the adrenal cortex. The final differentiation from noradrenaline-producing precursors to adrenaline-synthezising chromaffin cells takes place first in close vicinity to the steroid-producing adrenal cortex and may therefore be stimulated by glucocorticoids (Seidl and Unsicker 1989). The morphological basis of the glucocorticoid transfer from the cortex to the medulla is the special arrangement of a cortico-medullary capillary system (Murakami et al. 1989). Cortical blood rich in glucocorticoids flows via cortical capillaries into the corticomedullary venous radicles, subcortical veins and medullary collecting veins (Murakami et al. 1989). Cells of the outer zone of the adrenal medulla are therefore exposed to the highest glucocorticoid concentrations and are the first medullary cells to be differentiated into chromaffin adrenaline-producing cells. In conclusion, the adrenal cortex produces gluco- corticoids prior to its differentiation into three morphologically distinct zones.

Acknowledgements Mrs. Settles-Urban and Mrs. Roming contributed significantly to this work with their expert technical assistance.

\section{References}

Banks P, Helle K (1965) The release of protein from the stimulated adrenal medulla. Biochem J 97:40c

Benedum UM, Bauerle PA, Konecki DS, Frank R, Powell J, Mallet J, Huttner B (1986) The primary structure of bovine chromogranin A: a representative of a class of acidic secretory proteins common to a variety of peptidergic cells. EMBO J 5:1495-1502

Bohn MC, Goldstein M, Black I (1981) Role of glucorticoids in expression of the adrenergic phenotype in rat embryonic adrenal gland. Dev Biol 82:1-10

Cochard P, Goldstein M, Black I (1978) Ontogenetic appearance and disappearance of tyrosine hydroxylase and catecholamines in the rat embryo. Proc Natl Acad Sci USA 75:29862990

Deftos LJ (1991) Chromogranin A: its role in endocrine function and as an endocrine and neuroendocrine tumor marker. Endocrinol Rev 12:181-187

Eiden LE (1987) Is chromogranin a prohormone? Nature 325:301

Erhart M, Grube D, Bader M, Aunis D, Gratzl M (1986) Chromogranin $A$ in the pancreatic islet: cellular and subcellular distribution. J Histochem Cytochem 34:1673-1682

Hsu SM, Raine L, Fanger H (1981) Use of avidin-biotin-peroxidase complex $(\mathrm{ABC})$ in immunoperoxidase techniques: a comparison between $\mathrm{ABC}$ and unlabelled antibody (PAP) procedures. Histochem Cytochem 29:577-580

Kent C, Coupland RE (1989) Localization of chromogranin A and B, met-enkephalin-arg-gly-leu and PGP9. 5-like immunoreactivity in the developing and adult rat adrenal medulla and extra-adrenal chromaffin tissue. J Anat 166:213-225

Molenaar WS, Lee VMY, Trojanowski JQ (1990) Early fetal acquisition of the chromaffin and neuronal immunophenotype by human adrenal medullary cells. An immunohistological study using monoclonal antibodies to chromogranin A, synaptophysin, tyrosine hydroxylase, and neuronal cytoskeletal proteins. Exp Neurol 108:1-9

Murakami T, Oukouchi H, Uno Y, Ohtsuka A, Taguci T(1989) Blood vascular beds of rat adrenal and accessory glands, with special reference to the corticomedullary portal system: a further scanning electron microscopic study of corrosion casts and tissue specimens. Arch Histol Cytol 52:461-476

Reiffen FU, Gratzl M (1986a) Chromogranins, widespread in endocrine and nervous tissue, bind $\mathrm{Ca}^{++}$. FEBS Lett 195:327

Reiffen FU, Gratzl M (1986 b) $\mathrm{Ca}^{2+}$-binding to chromaffin vesicle matrix proteins: effect of $\mathrm{pH}, \mathrm{Mg}^{2+}$ and ionic strength. Biochemistry $25: 4402$

Rohrer H, Acheson AL, Thibault J, Thoenen H (1986) Developmental potential of quail dorsal root ganglion cells analyzed in vitro and in vitro. J Neurosci 6:2616-2624

Romeis B (1989) Nebennieren und chromaffines Gewebe. In: Mikroskopische Technik, 17. Urban \& Schwarzenberg, München Wien Baltimore, pp 621-623

Seidl K, Unsicker K (1989) The determination of the adrenal medullary cell fate during embryogenesis. Dev Biol 136:481490

Sternberger LA (1986) Immunohistochemistry, 3rd edn. Wiley, New York

Winkler H, Fischer-Colbrie R (1992) The chromogranins A and $\mathrm{B}$ : the first 25 years and future perspectives. Neuroscience 49:497-528 